\title{
Validation of the adapted Leeds sleep evaluation questionnaire in Ethiopian university students
}

\author{
Md. Dilshad Manzar ${ }^{1,2^{*}}$ (D) Mohammed Salahuddin ${ }^{3}$, Tarekegn Tesfaye Maru ${ }^{2}$, Ahmad Alghadir ${ }^{4}$, Shahnawaz Anwer ${ }^{4}$, \\ Ahmed S. Bahammam ${ }^{5,6}$ and Seithikurippu R. Pandi-Perumal ${ }^{7}$
}

\begin{abstract}
Background: Current evidence supports the applicability of the Leeds Sleep Evaluation Questionnaire (LSEQ) in screening for insomnia. The psychometric properties of the LSEQ have never been investigated in an African population. Therefore, this study aimed to validate the adapted version of the LSEQ-Mizan (LSEQ-M) in Ethiopian university students.

Methods: Of a preliminary sample of 750 (random sampling), 424 students (age $=21.87 \pm 4.13$ years and body mass index $=20.84 \pm 3.18 \mathrm{~kg} / \mathrm{m}^{2}$ ) from Mizan-Tepi University, Mizan-Aman, South-west Ethiopia completed the LSEQ-M, the General Anxiety Disorder Scale-7 and a semi-structured questionnaire for socio-demographics. Insomnia was screened in accordance with the International Classification of Sleep Disorders as a measure of concurrent validity.

Results: Although, individual items showed ceiling and floor effect, the LSEQ-M as a scale did not have these effects. Good internal consistency (Cronbach's alpha of 0.84) and strong internal homogeneity as measured by the correlation coefficient between items scores and the LSEQ-M global score was found. The LSEQ-M showed excellent screening applicability for insomnia with optimal cut-off scores of 52.6 (sensitivity 94\%, specificity 80\%), and the area under the curve, $0.95(p<0.0001)$. The original 4-Factor model was valid in Ethiopian university students for screening for insomnia.
\end{abstract}

Conclusion: The LSEQ-M has excellent psychometric validity in screening for insomnia among Ethiopian university students.

Keywords: LSEQ, Ethiopia, Insomnia, University students, Sleep

\section{Background}

The growing endemicity of sleep disorders is becoming a health concern around the globe [1-4]. The scarcity of sleep health infrastructure along with lack of awareness about sleep health issues in developing societies are obstructing the provision of patient care [5]. Young adults in general and university students in particular are at increased risk of sleep disorders $[4,6]$. Sleep problems are highly prevalent in university students in Afro-

\footnotetext{
* Correspondence: m.manzar@mu.edu.sa; md.dilshadmanzar@gmail.com 1 Department of Nursing, College of Applied Medical Sciences, Majmaah University, Al Majmaah, Kingdom of Saudi Arabia

${ }^{2}$ Department of Biomedical Sciences, College of Health Sciences, Mizan-Tepi University (Mizan Campus), Mizan-Aman, Ethiopia

Full list of author information is available at the end of the article
}

Asian countries [1-3, 7]. Most university students in Ethiopia have sleep problems associated with poor psychological health $[2,3]$. Sleep problems prevail in poor psycho-physiological health conditions such as stress, anxiety, fatigue, depression, attention deficit, reduced cognitive performance, and impaired social relationships. Sleep disturbances are associated with risk-taking behavior, drowsy driving, poor academic performance, and overall poor health among young adults including university students $[2,3,8,9]$.

Sleep disturbances in Ethiopian university students are related to insomnia and its associated conditions i.e. problems in sleep onset, short sleep duration and poor sleep quality $[2,3]$. Ethiopia also has high prevalence of 
predisposing factors for sleep disorders such as use of alcohol, Khat, and excessive use of caffeinated beverages $[2,3,5,7]$. The situation becomes grimmer because of the limited sleep health professionals in the country [7]. Few sleep questionnaire tools have been validated in Ethiopians. More so, there is no tool, which has been comprehensively validated in Ethiopian students. The Pittsburgh Sleep Quality Index (PSQI) was found to have adequate measures of psychometric characteristics in community dwelling Ethiopian adults but some aspects of its validity like dimensionality are still unresolved [7, 10-12]. Therefore, efforts to provide a valid and easy to use questionnaire tool to assess sleep health in Ethiopians students are needed.

The Leeds Sleep Evaluation Questionnaire (LSEQ) is a widely used tool for the diagnosis of sleep disorders including insomnia [13, 14]. The LSEQ was developed to monitor sleep changes during psychopharmacological investigations [14-16]. Available evidence indicates that the LSEQ can be adapted for application in nonpharmacological settings [17]. The psychometric properties of the LSEQ have not been investigated in the African population including Ethiopians. The present study therefore sought to validate the adapted version of the LSEQ (LSEQ-M) in a sample of Ethiopian university students.

\section{Methods}

A sample of 750 students was selected by simple random sampling method across Mizan campus of the Mizan-Tepi University, Mizan-Aman town, Bench Maji Zone, Southwest, Ethiopia. Four hundred and twenty four completed the cross-sectional study i.e. provided filled in answers for LSEQ, Generalized Anxiety Disorder Scale-7 (GAD-7), sub-structured questionnaire for socio-demographics, and participated in a clinical interview. The majority of the participants were males $(82.5 \%$ ), and young adults (age $=21.87 \pm 4.13$ years, and body mass index $\left.=20.84 \pm 3.18 \mathrm{~kg} / \mathrm{m}^{2}\right)$. Self-reported problems with memory was the exclusion criteria. The purpose and procedures of the study were explained to the volunteers in detail. The university students comprised of many ethnicities, some of them had limited reading proficiency level of the national language i.e. Amharic [7]. Therefore, the modified version of the tool called LSEQ-Mizan (LSEQ-M) (Additional file 1) and the original version of GAD-7 were administered in English by the instructor to the participants [18].

The LSEQ is composed of10 self-reported items each of which is scored on $100 \mathrm{~mm}$ visual analogue scale. These items are related to the ease of getting to sleep (GTS), quality of sleep (QOS), ease of awakening from sleep (AFS) and alertness and behavior following wakefulness (BFW) [14]. The items were adapted and modified to make it suitable for screening of sleep problems in university students. This adapted and modified English version of the LSEQ used is referred as LSEQMizan (LSEQ-M). 'Usual' was replaced with 'normal' from questions related to the GTS and the AFS in the LSEQ-M compared to LSEQ. 'More difficult than usual', 'easier than usual,' 'slower than usual,' 'more quickly than usual,' 'I feel less sleepy than usual', 'more sleepy than usual' were replaced by 'difficult,' 'easier,' 'slower', 'more quicker,' 'less sleepy, and 'more sleepy' respectively in the three items of the GTS in the LSEQ-M compared to the LSEQ. The phrase 'than usual' was deleted from the two items of the QOS and last item of the BFW in the LSEQ-M compared to the LSEQ. 'More difficult than usual,' 'easier than usual,' 'requires a period of time longer than usual, 'shorter than usual' were replaced by 'more difficult,' 'easier, 'requires longer period of time', and 'requires shorter period of time' respectively in the two items of the AFS in the LSEQ-M compared to the LSEQ. The reported score for each item was divided by 10 to get an individual item score between 0 and 10. Such scores (between 0 and 10) for each item were added to get LSEQ-M global score with a range of 0-100. EFA in our sample did not support the original 4-factor structure; therefore, we did not adopt the original scoring guideline [16]. In our adapted LSEQ-M, on each item of $100 \mathrm{~mm}$ visual analogue, 0 indicated worst sleep condition and 100 suggested normal state. The visual analog scale in the LSEQ-M was marked at intervals of 10 unlike the original LSEQ. Therefore, lower scores of the adapted LSEQ-M indicated poor sleep.

An experienced sleep researcher blinded to the LSEQ$\mathrm{M}$ score clinically interviewed all the participants who completed the study. The presence of insomnia was determined according to the International Classification of Sleep Disorders, revised criteria (ICSD-3) [7, 19]. These criteria included: (i) Insufficient amount of sleep almost every night, (ii) Feeling of restlessness after usual sleep and (iii) At least mild impairment of social or occupational functioning, (iv) Self-reported restlessness, irritability, anxiety, daytime fatigue, and tiredness. The students were classified as insomniacs if they had either of the first two conditions (i.e. i or ii), and at least mild complaints related to both (iii) and (iv) $[1,19]$. LSEQ-M has been found to be a valid and reliable measure of insomnia in French and Israeli populations [14].

\section{Statistical analysis}

The statistical analysis was performed using SPSS version 16.0 (SPSS Inc., Chicago, USA) along with AMOS (Analysis of Moment Structures, an add-on module). Internal consistency was assessed by the Cronbach alpha test, while internal homogeneity was tested by Pearson's correlation analysis between LSEQ-M items and the 
Table 1 Socio-demographics of Ethiopian university students

\begin{tabular}{|c|c|}
\hline Characteristics & Mean \pm SD/ Frequency \\
\hline Age $(y r)$ & $21.87 \pm 4.13$ \\
\hline $\mathrm{BMI}\left(\mathrm{Kg} / \mathrm{m}^{2}\right)$ & $20.84 \pm 3.18$ \\
\hline \multicolumn{2}{|l|}{ Gender } \\
\hline Male & $350(82.5 \%)$ \\
\hline Female & $74(17.5 \%)$ \\
\hline \multicolumn{2}{|l|}{ Ethnicity } \\
\hline Bench & $33(7.8 \%)$ \\
\hline Kaffa & $15(3.5 \%)$ \\
\hline Oromo & 129(30.4\%) \\
\hline Amhara & 139(32.8\%) \\
\hline Tigre & $3(0.7 \%)$ \\
\hline Wolaita & $8(1.9 \%)$ \\
\hline Others & $97(22.9 \%)$ \\
\hline \multicolumn{2}{|l|}{ Religion } \\
\hline Orthodox Christian & $208(49.1 \%)$ \\
\hline Protestants Christian & $136(32.1 \%)$ \\
\hline Catholic & $1(0.2 \%)$ \\
\hline Islam & $70(16.5 \%)$ \\
\hline Others & $9(2.1 \%)$ \\
\hline \multicolumn{2}{|l|}{ Years of university education } \\
\hline $1 \mathrm{yr}$ & 152(35.8\%) \\
\hline $2 \mathrm{yr}$ & 153(36.1\%) \\
\hline $3 \mathrm{yr}$ & $48(11.3 \%)$ \\
\hline $4 \mathrm{yr}$ & $38(9.0 \%)$ \\
\hline $5 \mathrm{yr}$ & $33(7.8 \%)$ \\
\hline \multicolumn{2}{|l|}{ Attendance } \\
\hline Upto $80 \%$ & $54(12.74 \%)$ \\
\hline $80-90 \%$ & $42(9.91 \%)$ \\
\hline $90-100 \%$ & $328(77.36 \%)$ \\
\hline \multicolumn{2}{|l|}{ Monthly Family Income (In Birr) } \\
\hline Very Low (less than 445) & $44(10.4 \%)$ \\
\hline Low (446-1200) & $78(18.4 \%)$ \\
\hline Average (1201-2500) & $55(13.0 \%)$ \\
\hline Above average (2501-3500) & $30(7.1 \%)$ \\
\hline High (greater than 3500) & $80(18.9 \%)$ \\
\hline Unknown & 137(32.3\%) \\
\hline \multicolumn{2}{|l|}{ Parents } \\
\hline Single & $180(42.5 \%)$ \\
\hline Married & $236(55.7 \%)$ \\
\hline Divorced & $8(1.9 \%)$ \\
\hline GAD-7 & $7.24 \pm 4.47$ \\
\hline \multicolumn{2}{|l|}{ Sleep } \\
\hline LSEQ score & $58.31 \pm 21.49$ \\
\hline \multicolumn{2}{|l|}{ ICSD-R Classification } \\
\hline Primary insomnia/normal & $133(31.4 \%) / 291(68.6 \%)$ \\
\hline \multicolumn{2}{|l|}{ Substance use/ Habits } \\
\hline Chat user/non-user & $18(4.2 \%) / 406(95.8 \%)$ \\
\hline Alcohol user/alcohol non-user & $23(5.4 \%) / 401(94.6 \%)$ \\
\hline
\end{tabular}

Table 1 Socio-demographics of Ethiopian university students (Continued)

\begin{tabular}{ll}
\hline Characteristics & Mean \pm SD/ Frequency \\
\hline Smoker/non-smoker & $2(0.5 \%) / 422(99.5 \%)$ \\
Tea/Coffee consumer/ non-consumer & $389(91.7 \%) / 35(8.3 \%)$ \\
Beverage consumer/beverage non-consumer & $253(59.7 \%) / 171(40.3 \%)$ \\
\hline BMI Body mass index; LSEQ, ICSD- $R$ International Classification of Sleep \\
Disorders, revised criteria, GAD-7 Generalized Anxiety Disorder-7
\end{tabular}

LSEQ-M global scores. Discriminative validity was assessed by independent $\mathrm{t}$-test for LSEQ-M item as well as the LSEQ-M global score. Diagnostic validity was evaluated by receiver operating curve (ROC) analysis. ICSD-3 based screening for primary insomnia by sleep expert served as the gold standard and the LSEQ-M global score was the test variable [19]. Area under the curve (AUC), cut off score, sensitivity and specificity were assessed.

Multivariate outliers were estimated by calculation of Mahalanobis distance (criterion of $\mathrm{a}=.001$ with $10 \mathrm{df}$ (number of variables), the critical $X^{2}=29.59$ ). Twenty two outliers were deleted for factor analysis with $X^{2}>$ 29.59 [20]. There was no issue of multicollinearity and singularity; high value of collinearity index of Tolerance and Condition Indexes less than 30 [21]. None of the items were skewed (Skewness $\mathrm{z}< \pm 3.29$ ); however, all were platykurtic (Kurtosis $\mathrm{z}>3.29$ ). Nevertheless, as the LSEQ-M is an established tool, no deletion or transformations of items was performed [21]. Exploratory factor analysis (EFA) was performed using Principal Axis Factoring extraction and direct oblimin rotation method.

Confirmatory factor analysis (CFA) was performed using maximum-likelihood extraction. The factor loadings (standardized estimates) of the LSEQ-M items on the latent factors were calculated. The CFA was run on six models of the LSEQ-M (Table 7); 1-Factor, 2-Factor correlated, 2-Factor uncorrelated, 4-Factor correlated, second order: 2-Factor, and second order: 4-Factor. Multiple fit indices from different categories; Goodness of fit index (GFI), Adjusted goodness of fit index (AGFI), Comparative Fit Index (CFI), root mean square error of approximation (RMSEA), expected cross-validation index (ECVI) and Chi square statistics were determined. These helped to evaluate the absolute adequate fit, as well as the relatively better fit of the models [20].

\section{Results}

The socio-demographics of the Ethiopian university students participating in the study are given in Table 1 . The mean LSEQ-M total score was $58.31 \pm 21.49$, and the prevalence of primary insomnia was $31.4 \%$. The vast majority of participants reported the habit of tea/coffee consumption (91.7\%), beverage intake (59.7\%) and class attendance above $90 \%$ (77.36\%) (Table 1). Table 2 shows 
Table 2 Descriptive statistics of the Leeds Sleep Evaluation Questionnaire (LSEQ) in Ethiopian university students

\begin{tabular}{|c|c|c|c|c|c|}
\hline \multirow{2}{*}{$\begin{array}{l}\text { Leeds Sleep Evaluation Questionnaire } \\
\text { (LSEQ) items }\end{array}$} & \multirow[t]{2}{*}{ Mean \pm SD } & \multicolumn{2}{|l|}{ Skewness } & \multicolumn{2}{|l|}{ Kurtosis } \\
\hline & & Skewness \pm SE & z & Kurtosis \pm SE & z \\
\hline Getting to sleep item 1 & $6.10 \pm 3.21$ & $-0.38 \pm 0.12$ & -3.08 & $-0.93 \pm 0.24$ & -3.82 \\
\hline Getting to sleep item 2 & $5.75 \pm 3.21$ & $-0.28 \pm 0.12$ & -2.30 & $-0.91 \pm 0.24$ & -3.76 \\
\hline Getting to sleep item 3 & $5.86 \pm 3.31$ & $-0.28 \pm 0.12$ & -2.25 & $-1.07 \pm 0.24$ & -4.40 \\
\hline Quality of sleep item 1 & $5.88 \pm 3.18$ & $-0.17 \pm 0.12$ & -1.35 & $-1.07 \pm 0.24$ & -4.39 \\
\hline Quality of sleep item 2 & $5.89 \pm 3.30$ & $-0.31 \pm 0.12$ & -2.51 & $-1.01 \pm 0.24$ & -4.17 \\
\hline Awake following sleep item 1 & $5.78 \pm 3.21$ & $-0.24 \pm 0.12$ & -1.96 & $-0.99 \pm 0.24$ & -4.07 \\
\hline Awake following sleep item 2 & $5.76 \pm 3.16$ & $-0.25 \pm 0.12$ & -2.07 & $-0.95 \pm 0.24$ & -3.91 \\
\hline Behaviour following wakening item 1 & $5.70 \pm 3.35$ & $-0.18 \pm 0.12$ & -1.49 & $-1.14 \pm 0.24$ & -4.70 \\
\hline Behaviour following wakening item 2 & $5.86 \pm 3.43$ & $-0.32 \pm 0.12$ & -2.61 & $-1.14 \pm 0.24$ & -4.67 \\
\hline Behaviour following wakening item 3 & $6.12 \pm 3.32$ & $-0.35 \pm 0.12$ & -2.86 & $-1.02 \pm 0.24$ & -4.18 \\
\hline
\end{tabular}

SD Standard deviation, SE Standard Error

the item analysis of the LSEQ-M in the study population. The presence of ceiling or floor effect was scored if more than $15 \%$ of respondents reported the highest or lowest score, respectively [7, 22, 23]. Overall, the LSEQ$\mathrm{M}$ total score did not have floor and ceiling effects; $0.9 \%$ of Ethiopian university students reported a minimum score of zero, and $7.5 \%$ reported a maximum score of 100. Only Item-9 showed floor effect but ceiling effect was observed for all the ten items [7, 22, 23]. The internal consistency test of the LSEQ-M showed a Cronbach's alpha of 0.84 , a value indicating good consistency. The internal homogeneity as shown by Pearson's correlation coefficient $(r)$ between item scores and the LSEQ$\mathrm{M}$ total score was $0.60-0.69$. All the correlation coefficients were significant $(p<0.01)$ (Table 3).

Table 3 Internal consistency and homogeneity of the Leeds Sleep Evaluation Questionnaire (LSEQ) scores in Ethiopian university students

\begin{tabular}{lll}
\hline Items of the LSEQ & $\begin{array}{l}\text { Item-to-global LSEQ } \\
\text { score correlations }\end{array}$ & $\begin{array}{l}\text { Cronbach's Alpha if } \\
\text { Item Deleted }\end{array}$ \\
\hline Getting to sleep item 1 & $.69^{* *}$ & .81 \\
Getting to sleep item 2 & $.62^{* *}$ & .82 \\
Getting to sleep item 3 & $.62^{* *}$ & .82 \\
Quality of sleep item 1 & $.65^{* *}$ & .82 \\
Quality of sleep item 2 & $.60^{* *}$ & .82 \\
Awake following sleep & $.67^{* *}$ & .82 \\
item 1 & \\
Awake following sleep & $.62^{* *}$ & .82 \\
item 2 & \\
Behaviour following & $.63^{* *}$ & .82 \\
wakening item 1 & & .82 \\
Behaviour following & $.64^{* *}$ & \\
wakening item 2 & & .82 \\
Behaviour following & $.62^{* *}$ & \\
wakening item 3 & & \\
**p< 0.01 & &
\end{tabular}

The groups of Ethiopian university students identified as normal and with moderate anxiety levels based on GAD-7 evaluation differed across the LSEQ-M total score, as well as scores of all the items score except the item-9 (Table 4). The diagnostic validity was assessed by the ROC curve (Fig. 1). The sensitivity and specificity of the LSEQ-M at the cut-off score of 52.6 were $94 \%$ and $80 \%$, respectively.

The sample satisfied the conditions for factor analysis as indicated by the results of Kaiser-Meyer-Olkin test of sampling adequacy, Bartlett's test of sphericity, antiimage matrix (Table 5) and communality retention criteria (0.37-0.57) (Table 6) [11, 24]. The three tests employed to estimate the number of factors in EFA i.e. Kaiser's criteria (Eigenvalue $>1$ ), Scree plot and cumulative variance rule $(>40 \%)$ found different number of factors. Kaiser's criteria (Eigenvalue $>1$ ) and Scree plot identified 2-factor model, while cumulative variance rule (> 40\%) found 1-factormodel for the LSEQ-M (Table 5). The loadings of the LSEQ-M items in EFA retained for performing CFA ranged from 0.34 to -0.90 (Table 6).

As indicated by significant $\mathrm{x}^{2} p$-value; none of the models had absolute fit to the data (Table 7). The results of the CFA did not validate the models indicated by EFA. The original 4-Factor correlated model performed best with lowest values for RMSEA, $\chi^{2} / \mathrm{df}, \chi^{2}$, and ECVI, while it showed highest values for GFI, AGFI and CFI (Table 7).

\section{Discussion}

This is the first study to examine the psychometric and diagnostic validity of the modified English version of the LSEQ in a non-pharmacological setting. In this study, the LSEQ-M was validated in Ethiopian university students using ICSD-R criteria for screening of insomnia. The individual items of the LSEQ-M had ceiling and floor effects but the LSEQ-M global score did not have either of these effects (Table 2). Thus, item analysis does 
Table 4 Discriminative validity: Comparison of the Leeds Sleep Evaluation Questionnaire (LSEQ) scores between Ethiopian university students with normal and moderate anxiety levels

\begin{tabular}{|c|c|c|c|c|c|}
\hline \multirow[t]{2}{*}{ Items of the LSEQ } & \multicolumn{2}{|l|}{ Mean (SD) score } & \multirow[t]{2}{*}{$t$} & \multirow[t]{2}{*}{$d f$} & \multirow[t]{2}{*}{$p$-value } \\
\hline & Normal $(n=125)$ & Moderate anxiety $(n=97)$ & & & \\
\hline Getting to sleep item 1 & $7.13(3.07)$ & $5.82(3.07)$ & 3.14 & 220 & .002 \\
\hline Getting to sleep item 2 & $6.68(3.32)$ & $4.96(3.02)$ & 4.01 & 212.50 & .006 \\
\hline Getting to sleep item 3 & $6.54(3.46)$ & $5.29(3.23)$ & 2.76 & 220 & $<0.001$ \\
\hline Quality of sleep item 1 & $7.16(2.94)$ & $5.42(3.16)$ & 4.22 & 220 & $<0.001$ \\
\hline Quality of sleep item 2 & $6.56(3.46)$ & $5.49(3.42)$ & 2.30 & 220 & .022 \\
\hline Awake following sleep item 1 & $6.59(3.34)$ & $4.87(3.07)$ & 3.94 & 220 & $<0.001$ \\
\hline Awake following sleep item 2 & $6.49(3.35)$ & $5.15(3.09)$ & 3.09 & 213.42 & .002 \\
\hline Behaviour following wakening item 1 & $6.62(3.42)$ & $4.66(3.26)$ & 4.31 & 220 & $<0.001$ \\
\hline Behaviour following wakening item 2 & $6.29(3.63)$ & $5.42(3.47)$ & 1.80 & 220 & .073 \\
\hline Behaviour following wakening item 3 & $6.85(3.31)$ & $5.55(3.31)$ & 2.89 & 220 & .004 \\
\hline LSEQ total score & $66.92(21.92)$ & $52.65(19.96)$ & 5.00 & 220 & $<0.001$ \\
\hline
\end{tabular}

*Mean \pm SD

support validity of the overall score of the scale [22]. Our findings did not show either ceiling or floor effects for the LSEQ-M. Similarly, neither ceiling nor floor effects were observed in the Korean version of the LSEQ global score [17].

The Cronbach's alpha test showed that the scale had good internal consistency in this population of Ethiopian university students. It is comparable to values reported in the French and Israeli insomniacs [14]. Tarrasch et al. [14] reported Cronbach's alpha values (0.78-0.92) for factors of the original 4-Factor model of the LSEQ. However, Kim et al. reported excellent value of Cronbach

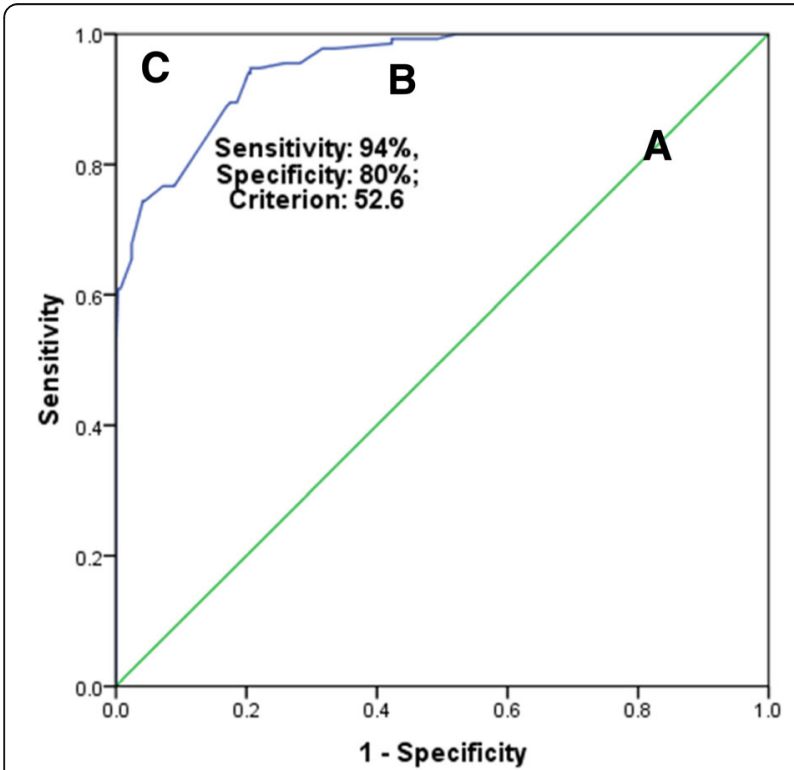

Fig. 1 Receiver operator curves (A) No discrimination (AUC =0.5) (B) Experimental test $(0.95(p<0.001))$ and $(C)$ Perfect test $(A \cup C=1.0)$ in Ethiopian university students alpha (.95) in Korean older adults [17]. There were little changes in Cronbach's alpha test if items were deleted suggesting almost similar relevance of items in the LSEQ-M construct (Table 3). The item-LSEQ-M global score had strong correlations (Table 3). Moreover, the close range of correlations suggests that all the 10 items are almost equally relevant for construct of the scale. This is unlike the case with PSQI, in which some items are less sensitive in particular populations $[4,7,25]$. Therefore, internal consistencies as well as internal homogeneity favor validity of the LSEQ-M over the PSQI in Ethiopians [7].

The significantly lower values of the LSEQ-M global as well as all the items (item-9) among those with moderate level of anxiety as measured by the GAD establish the diagnostic known-group or discriminative validity of the tool in this population of Ethiopian university students (Table 4). Insomnia has been shown to be associated with anxiety disorder [26]. Notably, with regard to discriminative validity as

Table 5 Summary of the sample size adequacy measures and exploratory factor analysis of the Leeds Sleep Evaluation Questionnaire (LSEQ) in Ethiopian university students

\begin{tabular}{ll}
\hline Measures & LSEQ (10-item scale) \\
\hline Kaiser-Meyer-Olkin Test of SamplingAdequacy & 0.85 \\
Bartlett's test of Sphericity & $<0.001$ \\
Anti-image matrix & $0.79-0.91$ \\
Determinant & 0.02 \\
Number of factors & \\
Kaiser's criteria (Eigenvalue> 1) & 2 \\
Cumulative variance rule $(>40 \%)$ & 1 \\
Scree plot & 2 \\
\hline
\end{tabular}

LSEQ Leeds Sleep Evaluation Questionnaire 
Table 6 Factor matrix of the 2-Factor model of the Leeds Sleep Evaluation Questionnaire (LSEQ) in Ethiopian university students

\begin{tabular}{llll}
\hline Leeds Sleep Evaluation Questionnaire (LSEQ) items & Factor-1 $^{\text {a }}$ & Factor-2 $^{{ }^{2}}$ & Communality (h2) \\
\hline Getting to sleep item 1 & .57 & -.20 & .46 \\
Getting to sleep item 2 & .72 & .04 & .45 \\
Getting to sleep item 3 & .76 & -.19 & .45 \\
Quality of sleep item 1 & .56 & .04 & .46 \\
Quality of sleep item 2 & .68 & -.77 & .37 \\
Awake following sleep item 1 & .02 & -.90 & .56 \\
Awake following sleep item 2 & -.12 & -.61 & .57 \\
Behaviour following wakening item 1 & .08 & -.38 & .42 \\
Behaviour following wakening item 2 & .29 & -.32 & .42 \\
Behaviour following wakening item 3 & .34 & .38 \\
\hline
\end{tabular}

Exploratory Factor analysis (EFA) with Principal Axis Factoring extraction and direct oblimin rotation method was performed

a Latent factors derived from EFA

well, the LSEQ-M has favorable validation than the PSQI in Afro-Asian populations [1, 4, 7].

The diagnostic validity of the scale against ICSD-3 criteria for insomnia in this sample of Ethiopian university students was in an excellent range [27]. Few studies have investigated the AUC of the LSEQ. The AUC of 0.95 (CI: 0.93-0.97) (Fig. 1) found in our study was higher than that reported in Korean older adults i.e. 0.86 (95\% CI: 0.83-0.90) [17]. Unlike our use of ICSD-3, Kim et al... had employed Insomnia Severity Index as the concurrent measure [17]. In Kim et al study the cut-off score was 66.5. However, as we had adopted a reverse scoring, the effective value of cut-off score from their study based on the reverse scoring will be 33.5 (100-66.5). Therefore, a cut-off score (52.6) (Fig. 1) for screening insomnia in our study sample of Ethiopian university students was higher than that reported in Korean older adults [17]. The accuracy (89\%) of the LSEQ-M at the cut-off score was higher than that reported in the Korean study [17]. This suggests that the LSEQ-M that was used in our study on Ethiopian university students had favorable diagnostic validity than the modified LSEQ used in Korean older adults [17]. The accuracy of the LSEQ-M in this study sample is also higher than the accuracy reported for the PSQI in Ethiopians [7]. Therefore, the
PSQI is probably only another sleep tool to be validated in Ethiopians for screening of insomnia as per ICSD-R criteria [7].

The results of the EFA were inconclusive, but the outcome of CFA favored the original 4-Factor model of the LSEQ-Min the Ethiopian university students (Tables 5, 6 and 7). The three factors in EFA suggested heterogeneity of the LSEQ factor structure (Tables 5 and 6). However, the original 4-Factor model of the LSEQ-M showed highest values for GFI, AGFI, CFI, and least values for $\chi^{2}, \chi^{2}$ /df, RMSEA and ECVI (Table 7). This favored the validity of the original 4-Factor model over all other models tested $[11,16,24]$.

Biased gender ratio in the study sample and nonapplication of objective measurement of sleep i.e. polysomnography, actigraphy are important limitations. The gender ratio in the study sample was 0.22 , although it is 0.55 in the university students. Female students were less likely to complete the clinical interview, which might have resulted in gender bias. The test re-test reliability and inter/intrarater reliability were not assessed. Future studies should look into this aspect. The merits include validation of a tool in a population, which has high prevalence of sleep problems but does not have access to advanced sleep medicine professionals and/or facilities.

Table 7 Fit statistics of the Leeds Sleep Evaluation Questionnaire (LSEQ) in Ethiopian university students

\begin{tabular}{|c|c|c|c|c|c|c|c|c|c|}
\hline Models & GFI & AGFI & $\mathrm{CFI}$ & RMSEA & $x^{2}$ & $\mathrm{df}$ & $p$ & $x^{2} / d f$ & $\overline{\mathrm{ECVI}}$ \\
\hline 1-Factor & .88 & .81 & .81 & $.12(.11-.14)$ & 267.17 & 35 & $<.001$ & 7.63 & .73 \\
\hline 2-Factor correlated & .92 & .87 & .87 & $.10(.09-.12)$ & 187.39 & 34 & $<.001$ & 5.51 & .54 \\
\hline 2-Factor uncorrelated & .87 & .81 & .75 & $.14(.13-.16)$ & 342.68 & 35 & $<.001$ & 9.79 & .91 \\
\hline 4-Factor correlated & .94 & .89 & .92 & $.09(.07-.10)$ & 121.50 & 29 & $<.001$ & 4.19 & .41 \\
\hline Second order: 2-Factor & .92 & .87 & .87 & $.10(.08-.12)$ & 187.39 & 34 & $<.001$ & 5.51 & .54 \\
\hline Second order: 4-Factor & .93 & .88 & .91 & $.09(.08-.11)$ & 145.16 & 31 & $<.001$ & 4.68 & .46 \\
\hline
\end{tabular}

GFI Goodness of fit index, AGFI Adjusted goodness of fit index, CFI Comparative Fit Index, RMSEA root mean square error of approximation, ECVI ECVI expected cross-validation index 


\section{Conclusion}

The study findings suggest that LSEQ has favorable psychometric validity than the PSQI in Ethiopians. The LSEQ-M was found to be a valid tool for screening for insomnia in this sample of Ethiopian university students.

\section{Additional file}

Additional file 1: (SAV $30 \mathrm{~kb})$

\section{Acknowledgements}

We are grateful to the participants of the study. The authors are grateful to the Mizan-Tepi University and the Deanship of Scientific Research, King Saud University (through Vice Deanship of Scientific Research Chairs) for providing the running cost of the project.

\section{Funding}

No funding has been reported for this study.

\section{Authors' contributions}

MDM: Concept development and study design, analysis and interpretation, manuscript preparation, critical revision of the manuscript, and approved the final version of the manuscript. MS: Data acquisition, interpretation, and approved the final version of the manuscript. TTM: data acquisition, interpretation, and approved the final version of the manuscript. AA: Concept development, critical revision of the Manuscript, and approved the final version of the manuscript. SRP: Concept development, critical revision of the manuscript, and approved the final version of the manuscript. SA: Data acquisition, analysis and interpretation, and approved the final version of the manuscript. ASB: Writing and critical revision of the manuscript, and approved the final version of the manuscript. All authors read and approved the final manuscript.

\section{Ethics approval and consent to participate}

The study was approved by the Human Institutional Ethics Committee of Mizan-Tepi University, and informed consent was obtained from all participants.

\section{Consent for publication}

Not applicable.

\section{Competing interests}

The authors declare that they have no competing interests.

\section{Publisher's Note}

Springer Nature remains neutral with regard to jurisdictional claims in published maps and institutional affiliations.

\section{Author details}

${ }^{1}$ Department of Nursing, College of Applied Medical Sciences, Majmaah University, Al Majmaah, Kingdom of Saudi Arabia. ${ }^{2}$ Department of Biomedical Sciences, College of Health Sciences, Mizan-Tepi University (Mizan Campus), Mizan-Aman, Ethiopia. ${ }^{3}$ Department of Pharmacy, College of Health Sciences, Mizan-Tepi University (Mizan Campus), Mizan-Aman, Ethiopia. ${ }^{4}$ Rehabilitation Research Chair, College of Applied Medical Sciences, King Saud University, Riyadh, Saudi Arabia. ${ }^{5}$ The University Sleep Disorders Center, College of Medicine, King Saud University, Box 225503, Riyadh 11324, Saudi Arabia. ${ }^{6}$ National Plan for Science and Technology, College of Medicine, King Saud University, Riyadh, Saudi Arabia. ${ }^{7}$ Somnogen Canada Inc, College Street, Toronto, ON, Canada.
}

Received: 23 October 2017 Accepted: 8 March 2018

Published online: 13 March 2018

\section{References}

1. Aloba OO, Adewuya AO, Ola BA, Mapayi BM. Validity of the Pittsburgh sleep quality index (PSQI) among Nigerian university students. Sleep Med. 2007;8: 266-70

2. Lemma S, Gelaye B, Berhane Y, Worku A, Williams MA. Sleep quality and its psychological correlates among university students in Ethiopia: a crosssectional study. BMC Psychiatry. 2012;12:237.

3. Lemma S, Patel SV, Tarekegn YA, Tadesse MG, Berhane Y, Gelaye B, Williams MA. The epidemiology of sleep quality, sleep patterns, consumption of caffeinated beverages, and Khat use among Ethiopian college students. Sleep Disord. 2012;2012:583510

4. Manzar MD, Zannat W, Kaur M, Hussain ME. Sleep in university students across years of university education and gender influences. Int J Adolesc Med Health. 2015;27:341-8.

5. Manzar MD, Salahuddin M, Maru TT, Dadi TL, Abiche MG, Abateneh DD, Pandi-Perumal SR, Bahammam AS. Sleep correlates of substance use in community-dwelling Ethiopian adults. Sleep Breath. 2017;21:1005-11.

6. Tsui YY, Wing YK. A study on the sleep patterns and problems of university business students in Hong Kong. J Am Coll Health. 2009;58:167-76.

7. Salahuddin M, Maru TT, Kumalo A, Pandi-Perumal SR, Bahammam AS, Manzar MD. Validation of the Pittsburgh sleep quality index in community dwelling Ethiopian adults. Health Qual Life Outcomes. 2017;15:58.

8. Gaultney JF. The prevalence of sleep disorders in college students: impact on academic performance. J Am Coll Health. 2010;59:91-7.

9. Sweileh WM, Ali IA, Sawalha AF, Abu-Taha AS, Zyoud SH, Al-Jabi SW. Sleep habits and sleep problems among Palestinian students. Child Adolesc Psychiatry Ment Health. 2011;5:25.

10. Koh HW, Lim RB, Chia KS, Lim WY. The Pittsburgh sleep quality index in a multi-ethnic Asian population contains a three-factor structure. Sleep Breath. 2015;19:1147-54.

11. Manzar MD, Zannat W, Hussain ME, Pandi-Perumal SR, Bahammam AS, Barakat D, Ojike NI, Olaish A, Spence DW. Dimensionality of the Pittsburgh sleep quality index in the collegiate young adults. Springer Plus. 2016;5: 1550.

12. Gelaye B, Lohsoonthorn V, Lertmeharit S, Pensuksan WC, Sanchez SE, Lemma S, Berhane Y, Zhu X, Velez JC, Barbosa C, et al. Construct validity and factor structure of the Pittsburgh sleep quality index and Epworth sleepiness scale in a multi-national study of African, south east Asian and south American college students. PLoS One. 2014;9:e116383.

13. Karsten J, Hagenauw LA, Kamphuis J, Lancel M. Low doses of mirtazapine or quetiapine for transient insomnia: a randomised, double-blind, cross-over, placebo-controlled trial. J Psychopharmacol (Oxf). 2017;31:327-37.

14. Tarrasch R, Laudon M, Zisapel N. Cross-cultural validation of the Leeds sleep evaluation questionnaire (LSEQ) in insomnia patients. Hum Psychopharmacol. 2003;18:603-10.

15. Parrott AC, Hindmarch I. The Leeds sleep evaluation questionnaire in psychopharmacological investigations - a review. Psychopharmacology. 1980;71:173-9.

16. Parrott AC, Hindmarch I. Factor analysis of a sleep evaluation questionnaire. Psychol Med. 1978:8:325-9.

17. Kim I, Choi HJ, Kim B. Psychometric properties of Korean version of modified Leeds sleep evaluation questionnaire (KMLSEQ). Korean J Rehabil Nurs. 2014;17:10-7.

18. Spitzer RL, Kroenke K, Williams JB, Lowe B. A brief measure for assessing generalized anxiety disorder: the GAD-7. Arch Intern Med. 2006;166:1092-7.

19. AASM. International classification of sleep disorders, revised: diagnostic and coding manual. Chicago: American Academy of Sleep Medicine; 2001

20. Jaccard J, Wan C. LISREL approaches to interaction effects in multiple regression. 1st ed. Thousand Oaks: SAGE Publications; 1996.

21. Tabachnick BG, Fidell LS. Using multivariate statistics. 6th ed. Boston: Pearson; 2013.

22. Lim CR, Harris K, Dawson J, Beard DJ, Fitzpatrick R, Price AJ. Floor and ceiling effects in the OHS: an analysis of the NHS PROMs data set. BMJ Open. 2015;5:e007765.

23. Terwee CB, Bot SD, de Boer MR, van der Windt DA, Knol DL, Dekker J, Bouter LM, de Vet HC. Quality criteria were proposed for measurement properties of health status questionnaires. J Clin Epidemiol. 2007;60:34-42. 
24. Manzar MD, Zannat W, Moiz JA, Spence DW, Pandi-Perumal SR, Bahammam AS. Factor scoring models of the Pittsburgh sleep quality index: a comparative confirmatory factor analysis. Biol Rhythm Res. 2016;47:851-64.

25. Manzar MD, Moiz JA, Zannat W, Spence DW, Pandi-Perumal SR, Hussain ME. Validity of the Pittsburgh sleep quality index in Indian university students. Oman Med J. 2015;30:193-202

26. Johnson EO, Roth T, Breslau N. The association of insomnia with anxiety disorders and depression: exploration of the direction of risk. J Psychiatr Res. 2006; $40: 700-8$

27. Hanley JA, McNeil BJ. The meaning and use of the area under a receiver operating characteristic (ROC) curve. Radiology. 1982;143:29-36.

Submit your next manuscript to BioMed Central and we will help you at every step:

- We accept pre-submission inquiries

- Our selector tool helps you to find the most relevant journal

- We provide round the clock customer support

- Convenient online submission

- Thorough peer review

- Inclusion in PubMed and all major indexing services

- Maximum visibility for your research

Submit your manuscript at www.biomedcentral.com/submit
) Biomed Central 